\title{
A Note on Nonsurvey Input-Output Models for Multicounty Regions
}

\author{
Mark Henry* \\ INTRODUCTION
}

Despite the continuing debate on the relative merits of survey, nonsurvey and semi-survey methods of estimating regional input-output (IO) models, (see 1,2$)$ nonsurvey techniques are widely used because of their low cost. Among these low cost alternatives that use published regional data and the national IO tables, the simple location quotient (SLQ) approach has been found to yield the most accurate estimates of regional IO tables $(2,3,4)$.

The purpose of this note is to demonstrate the need for a modification of the SLQ approach whenever this method is used to estimate an aggregate regional IO model and subregional IO models that are components of the aggregate region.

\section{SIMPLE LOCATION QUOTIENT METHOD}

The simple location quotient (SLQ) approach for regionalizing a national IO model may be summarized as follows.

First, location quotients are calculated for each sector in region (k) using the formula:

$$
\mathrm{LQ}_{\mathrm{ik}}=\left(\mathrm{E}_{\mathrm{ik}} / \sum_{\mathrm{i}=1}^{\mathrm{n}} \mathrm{E}_{\mathrm{ik}}\right) \div\left(\sum_{\mathrm{k}=1}^{\mathrm{m}} \mathrm{E}_{\mathrm{ik}} / \sum_{\mathrm{i}=1}^{\mathrm{n}} \sum_{\mathrm{k}=1}^{\mathrm{m}} \mathrm{E}_{\mathrm{ik}}\right)
$$

where $E_{i k}$ is the employment in the $i^{\text {th }}$ industry in region $k$ and $L_{i k}$ is the location quotient for industry $\mathrm{i}$ and region $\mathrm{k}$ in a nation with $\mathrm{n}$ industries and $\mathrm{m}$ regions. The location quotients for each regional industry $\mathrm{i}$ are then used to adjust national technical coefficients for that same industry so that:

$$
\mathrm{k}_{\mathrm{a}_{\mathrm{ij}}}=\mathrm{a}_{\mathrm{ij}} \text { if } L Q_{\mathrm{i}} \geq 1
$$

or

$$
\mathrm{k}_{\mathrm{a}_{\mathrm{ij}}}=\left(\mathrm{a}_{\mathrm{ij}}\right)\left(\mathrm{LQ}_{\mathrm{i}}\right) \text { if } \mathrm{LQ}_{\mathrm{i}}<1
$$

where $\mathrm{k}_{\mathrm{a}_{\mathrm{j}}}$ is the adjusted technical coefficient for industry $\mathrm{i}$ in region $\mathrm{k}$. In effect, if the regional location quotient for a given industry is less than unity,

*Associate Professor, Agricultural Economics, and Rural Sociology, Clemson University. 
each coefficient in the row of the national matrix representing that industry is adjusted downward by multiplying industry technical coefficients by the industry location quotient. These new coefficients are then used with regional outputs total $\left(\mathrm{k}_{\mathrm{X}_{\mathrm{j}}}\right)$ to estimate regional transactions, or:

$$
\mathrm{k}_{\mathrm{X}_{\mathrm{ij}}}=\left(\mathrm{k}_{\mathrm{X}_{\mathrm{j}}}\right)\left(\mathrm{k}_{\mathrm{a}_{\mathrm{ij}}}\right), \mathrm{i}=1 \ldots \mathrm{n}, \text { all } \mathrm{j}
$$

and each estimated transactions element $\left(\mathrm{k}_{\mathrm{X}_{\mathrm{ij}}}\right)$ is then adjusted so that:

$$
\mathrm{k}_{\bar{X}_{\mathrm{ij}}}=\mathrm{k}_{\mathrm{X}_{\mathrm{ij}}} \text { if } \sum_{\mathrm{j}} \mathrm{k}_{\mathrm{X}_{\mathrm{ij}}} \geq \mathrm{k}_{\mathrm{X}_{\mathrm{i}}},\left(\mathrm{k}_{\mathrm{X}_{\mathrm{i}}}=\mathrm{k}_{\mathrm{X}_{\mathrm{j}}}\right)
$$

or

$$
\mathrm{k}_{\bar{X}_{\mathrm{ij}}}=\mathrm{k}_{\mathrm{X}_{\mathrm{ij}}}\left(\mathrm{k}_{\mathrm{X}_{\mathrm{i}}} / \sum_{\mathrm{j}} \mathrm{k}_{\mathrm{X}_{\mathrm{ij}}}\right) \text { if } \underset{\mathrm{j}}{\Sigma} \mathrm{k}_{\mathrm{X}_{\mathrm{ij}}} \geq \mathrm{k}_{\mathrm{X}_{\mathrm{i}}}
$$

where $\mathrm{k}_{\overline{\mathrm{X}}_{\mathrm{i}}}$ is the estimated regional transactions element. Essentially, the adjustment in equations 5 and 6 prevents the in-region sales of a sector from exceeding the gross output of that sector. Once the transactions elements, $\mathrm{k}_{\bar{X}_{\mathrm{ij}}}$ have been estimated, the usual procedures may be used to determine the regional direct requirements and total requirements tables:

$$
\begin{aligned}
& a_{i j}^{r}=\frac{k_{\bar{x}_{i j}}}{\sum_{i=1}^{n} k_{\bar{X}_{i j}}} \quad, \quad A^{r}=\frac{a_{11}^{r} a_{12}^{r} \ldots a_{1 n}^{r}}{a_{21}^{r} .} . \\
& a_{n 1}^{r} \quad \cdot a_{n n}^{r}
\end{aligned}
$$

and $\left(\mathrm{I}-\mathrm{A}^{\mathrm{r}}\right)^{-1}$

\section{THE SLQ MULTICOUNTY PROBLEM}

Despite the simplicity and accuracy of the SLQ approach when compared to alternative nonsurvey approaches, a conceptual problem exists when a multicounty set of IO models is constructed with the SLQ approach. The problem is that subregions (e.g., counties) within a given region (e.g., a multicounty planning district) may have larger sectoral multipliers than the overall region. ${ }^{1}$ As an illustration of this problem, consider the case where a multicounty planning district in the region for which the SLQ method is used to estimate the $\mathrm{A}^{\mathrm{r}}$ and $\left(\mathrm{I}-\mathrm{A}^{\mathrm{r}}\right)^{-1}$ matrices. Furthermore, assume that matrices $\mathrm{A}$ [

'Reference here and in the ensuing discussion is to gross output multipliers when multipliers are mentioned. However, similar arguments may be made for other IO multipliers as well. 
and $\mathrm{I}-\mathrm{A} \ell)^{-1}$ are found for each of the $\ell$ counties in the region. Then, using the earlier notation, the location quotients for the region and each county in the region are found as follows for the multicounty region $\mathrm{k}$ :

$$
L_{i k}=\left(E_{i k} / \sum_{i=1}^{n} E_{i k}\right) \div\left(\sum_{k=1}^{n} E_{i k} / \sum_{i=1}^{n} \sum_{k=1}^{m} E_{i k}\right)
$$

For each county, $l$, within region $\mathrm{k}$ :

$$
L_{i k l}=\left(E_{i k \ell} / \sum_{i}^{n} E_{i k \ell}\right) \div\left(\sum_{k=1}^{m} E_{i k} / \sum_{i=1}^{n} \sum_{k=1}^{m} E_{i k}\right)
$$

Although $\sum_{l=1}^{c} E_{i k \ell}=E_{i k}$, there is no reason to expect that the first ratio in equations (9) and (10) will be equal. In fact, for a county that has a larger proportion of its employment in a given sector then the region proportion, the county LQ will exceed the regional LQ for that sector. This is the crux of the problem. For the county where $\mathrm{LQ}_{\mathrm{ik}} \ell>\mathrm{LQ}_{\mathrm{ik}}$, it follows from equation (2) and (3) that the $\mathrm{k}_{\text {aij }}$ coefficients will be higher for the county for the $i^{\text {th }}$ sector. That is, the $\mathrm{i}^{\text {th }}$ row in the $\mathrm{A}^{\mathrm{r}}$ matrix will have larger coefficients in the county level matrix than in the regional level matrix. Thus, each sector in the county will purchase more from sector $i$ in the county than they do from the region. This is clearly wrong since the county is part of the region so that within region purchases should be equal to or greater than within county purchases.

\section{THE SLQ MULTICOUNTY PROBLEM - A SOLUTION}

To remedy the multicounty problem encountered when using the SLQ method, a search for the maximum subregion $L_{i}$ among the subregions that comprise the region is made. By using the maximum $L_{\mathrm{ik}} l$ (MAXLQ) as representative of the entire region, multiplier inconsistency may be avoided. This procedure ensures that the resulting $\mathrm{A}^{\mathrm{r}}$ matrix for the region will have values that contain column sums that are greater than or equal to the column sums of the $\mathrm{A}_{l}^{\mathrm{r}}$ matrices of the subregions. In addition, use of this method only requires the additional assumption beyond the SLQ approach that aggregate regional sectoral specialization is at least as great as the component subregional sectoral specialization. This implies that subregions will purchase inputs from the most specialized subregional sectors (highest $L Q_{i k} \ell$ ) within the aggregate region. ${ }^{2}$

${ }^{2} \mathrm{~A}$ reviewer has noted that multiplier consistency can be ensured by using the following substitute for equation (10):

$$
L Q_{i k \ell}=\left(E_{i k \ell} / \sum_{i=1}^{n} E_{i k \ell}\right) \div\left(\sum_{l}^{c} E_{i k \ell} / \sum_{i}^{n} \underset{l}{c} E_{i k \ell}\right) .
$$

This procedure assumes that the analyst is willing to derive county models from the nonsurvey regional tables. 


\section{CONCLUSION AND SUMMARY}

Use of the SLQ approach to estimating nonsurvey regional IO models can lead to inconsistent results if a set of multicounty IO models is to be estimated. The MAXLQ approach described in this article eliminates the inconsistency. Further, the MAXLQ approach is based on the intuitively appealing assumption that an aggregate region is at least as specialized in the production of goods and services as its component subregions.

\section{REFERENCES}

1. Miernyk, W. H., "Comments on Recent Development in. Regional Input-Output Analysis." International Regional Science Review, 1 (Fall, 1968), pp. 47-55.

2. Morrison, W. I. and Smith, P., "Nonsurvey Input-Output Technique at the Small Area Level: An Evaluation," Journal of Regional Science, 14(February, 1974), pp. 1-14.

3. Schaffer, W. A., "Estimating Regional InputOutput Coefficients," The Review of Regional Studies, 2(Spring, 1972), pp. 57-71.
4. _ and Chu, K., "Nonsurvey Technique for Constructing Regional Interindustry Models," Papers, Regional Science Association, 23(1969), pp. 83-101.

5. Stevens, B. H. and Trainer, G. A., "Error Generation in Regional Input-Output Analysis and Its Implications for Nonsurvey Models,' Discussion Paper No. 108, Philadelphia: Regional Science Research Institute (December 1978). 